\title{
Short-Term Topical Bevacizumab in the Treatment of Stable Corneal Neovascularization
}

\section{Citation}

Cheng, Sheng-Fu, Mohammad H. Dastjerdi, Giulio Ferrari, Andre Okanobo, Kraig S. Bower, Denise S. Ryan, Francisco Amparo, et al. 2012. "Short-Term Topical Bevacizumab in the Treatment of Stable Corneal Neovascularization." American Journal of Ophthalmology 154 (6) (December): 940-948.e1. doi:10.1016/j.ajo.2012.06.007.

\section{Published Version}

10.1016/j.ajo.2012.06.007

\section{Permanent link}

http://nrs.harvard.edu/urn-3:HUL.InstRepos:34428281

\section{Terms of Use}

This article was downloaded from Harvard University's DASH repository, and is made available under the terms and conditions applicable to Other Posted Material, as set forth at http:// nrs.harvard.edu/urn-3:HUL.InstRepos:dash.current.terms-of-use\#LAA

\section{Share Your Story}

The Harvard community has made this article openly available.

Please share how this access benefits you. Submit a story.

\section{Accessibility}




\title{
Short-Term Topical Bevacizumab in the Treatment of Stable Corneal Neovascularization
}

\author{
Sheng-Fu Cheng ${ }^{1,2}$, Mohammad H. Dastjerdi ${ }^{1}$, Giulio Ferrari ${ }^{1}$, Andre Okanobo ${ }^{1}$, Kraig S. \\ Bower $^{3}$, Denise S. Ryan ${ }^{4}$, Francisco Amparo' ${ }^{1}$, William Stevenson ${ }^{1}$, Pedram Hamrah ${ }^{1}$, \\ Nambi Nallasamy ${ }^{1}$, and Reza Dana ${ }^{1}$ \\ ${ }^{1}$ Cornea Service, Massachusetts Eye \& Ear Infirmary, Department of Ophthalmology, Harvard \\ Medical School. 243 Charles Street, Boston, MA 02114 \\ ${ }^{2}$ Department of Ophthalmology, Shin Kong Wu Ho-Su Memorial Hospital. No. 95, Wen Chang \\ Road, Shih Lin District, Taipei City, Taiwan \\ ${ }^{3}$ Division of Cornea, Cataract, \& External Diseases, The Wilmer Eye Institute, The Johns Hopkins \\ School of Medicine. 600 N. Wolfe Street, Baltimore, MD 21287 \\ ${ }^{4}$ Ophthalmology Service, Walter Reed Army Medical Center. 6900 Georgia Avenue Northwest, \\ Washington, DC 20307
}

\begin{abstract}
Purpose-To evaluate the safety and efficacy of topical bevacizumab in the treatment of corneal neovascularization (NV).
\end{abstract}

Design-Prospective, non-randomized, interventional case series.

Setting-Institutional, multicenter clinical trial.

Study Population-Twenty eyes from 20 patients with stable corneal NV.

Intervention Procedures-Patients were treated with topical 1.0\% for 3 weeks and monitored for a total of 24 weeks.

Main Outcome Measures-Primary outcome measures included: neovascular area, defined as the area of the corneal vessels themselves; vessel caliber, defined as the mean corneal vessel diameter; and invasion area, defined as the fraction of the total cornea into which the vessels extended. The occurrence of ocular and systemic adverse events was closely monitored.

\footnotetext{
(C) 2012 Elsevier Inc. All rights reserved.

Corresponding Author: Reza Dana, MD, MPH, MSc, Cornea Service, Massachusetts Eye \& Ear Infirmary, 243 Charles Street, Boston, MA 02114, Phone: (617) 912-7401; Fax: (617) 912-0117, reza_dana@ meei.harvard.edu.

Financial Disclosures: None.

Contributions to Authors in each of these areas: Design of the study (MD, RD); conduct of the study (SFC, MD, KB, RD); collection of the data $(\mathrm{KB}, \mathrm{PH}, \mathrm{RD})$; management, analysis and interpretation of the data (SFC, MD, GF, AO, DR, FA, WS, NN, RD); preparation of the manuscript (SFC, WS, RD).

Statement about Conformity with Author Information: This was a prospective protocol driven study approved by the Institutional Review Boards (IRB) of Massachusetts Eye \& Ear Infirmary and Walter Reed Army Medical Center. The study was also HIPAA compliant. Informed consent was obtained from all patients before enrollment. The clinical trial was registered (registration number: NCT00559936) and can be accessed on the website www.clinicaltrials.gov.

Publisher's Disclaimer: This is a PDF file of an unedited manuscript that has been accepted for publication. As a service to our customers we are providing this early version of the manuscript. The manuscript will undergo copyediting, typesetting, and review of the resulting proof before it is published in its final citable form. Please note that during the production process errors may be discovered which could affect the content, and all legal disclaimers that apply to the journal pertain.
} 
Results-As compared to the baseline visit, patients exhibited a statistically significant improvement in neovascular area by week $6(P=.007)$ and vessel caliber by week $12(P=.006)$. At the final visit, neovascular area, vessel caliber, and invasion area were reduced by $47.5 \%$, $36.2 \%$, and $20 \%$, respectively. The decreases in neovascular area and vessel caliber were statistically significant $(P<.001$ and $P=.003$, respectively); however, the reduction in invasion area did not reach statistical significance $(P=.06)$. There were no significant changes in the secondary outcomes and there were no adverse events.

Conclusions-Short-term topical bevacizumab treatment reduced the extent of stable corneal $\mathrm{NV}$ as measured by neovascular area and vessel caliber with no associated adverse events. Interestingly, the degree of treatment efficacy was inversely proportional to the baseline invasion area.

\section{INTRODUCTION}

The healthy cornea is a unique tissue devoid of blood and lymphatic vessels. This feature is necessary for the maintenance of corneal transparency and visual acuity. Corneal neovascularization (NV) can result from a variety of insults including corneal infection, inflammation, trauma, degeneration, ischemia, and the loss of limbal stem cells. ${ }^{1}$ Corneal $\mathrm{NV}$ is a devastating complication of the most common infectious causes of blindness in developed (herpetic keratitis) ${ }^{2}$ and developing (trachoma) ${ }^{3}$ countries. The presence of corneal vessels can influence corneal inflammation, scarring, edema, and lipid deposition, all of which serve to decrease corneal transparency. ${ }^{4}$ In the case of corneal transplantation, ocular immune privilege, which helps extend the survival of corneal allografts, ${ }^{5}$ can be abrogated by corneal NV. ${ }^{6}$ In fact, the presence of stromal vessels in the host cornea is one of the strongest risk factors for subsequent graft failure. ${ }^{7}$

Angiogenesis is promoted by a complex array of microenvironmental changes that involve a diverse array of cellular and molecular mediators. ${ }^{8}$ Vascular endothelial growth factor (VEGF) is a key factor in the development of NV. ${ }^{9}$ Corneal epithelial cells, vascular endothelial cells, macrophages, and fibroblasts can produce VEGF. ${ }^{10}$ The production of VEGF is significantly elevated in inflamed and vascularized corneas. ${ }^{11,12}$ Bevacizumab (Avastin; Genentech; South San Francisco, CA) is a humanized, full-length, monoclonal anti-VEGF antibody that functions by binding and neutralizing VEGF, thereby inhibiting angiogenesis. Bevacizumab was first approved by the U.S. Food and Drug Administration in 2004 for the treatment of metastatic colorectal cancer. Since then, bevacizumab has been used 'off-label' to treat numerous cancers and a variety of ocular conditions including neovascular age-related macular degeneration, ${ }^{13}$ central retinal vein occlusion, ${ }^{14}$ proliferative diabetic retinopathy, ${ }^{15}$ iris $\mathrm{NV},{ }^{16}$ pterygium, ${ }^{17}$ and corneal NV.${ }^{18-20}$

Preliminary results from our study of topical bevacizumab in the treatment of corneal NV were published in $2009 .{ }^{18}$ We reported a statistically significant improvement in several measures of corneal NV with no associated adverse events. However, the limited number of patients in that study precluded the achievement of definitive conclusions regarding the relationship between medication efficacy and clinical factors such as the extent of corneal NV. Several studies, in some cases involving prolonged treatment, have reported complications associated with the administration of topical bevacizumab that were not identified in our preliminary study, including spontaneous corneal epitheliopathy, stromal thinning, and corneal perforation. ${ }^{19,20}$ The present study was limited to cases of stable corneal $\mathrm{NV}$ in order to avoid conditions such as pre-existing corneal epitheliopathy that may be associated with adverse events; moreover, the exclusion of active corneal NV potentially reduced the confounding effects of active ocular surface inflammation. Herein, we present the results of a clinical trial involving 20 cases of stable corneal $\mathrm{NV}$ treated with topical 
bevacizumab. Furthermore, we investigate potential correlations between treatment response and factors such as the extent of corneal NV and underlying disease state.

\section{METHODS}

Design

This was a prospective, open-label, multi-center, uncontrolled, single group, safety and efficacy study of bevacizumab administered topically to patients with corneal NV. Subjects were recruited and treated at either The Massachusetts Eye \& Ear Infirmary, Boston MA, or The Walter Reed Army Medical Center, Washington DC.

\section{Patient Selection}

Male and female adult patients were considered for study inclusion if they exhibited clinically stable corneal $\mathrm{NV}$ that extended at least $2 \mathrm{~mm}$ beyond the limbus. Clinical stability was established using the following exclusion criteria: (1) current or recent (3 months) ocular infection; (2) ocular surgery on the study eye within the previous 3 months; (3) current or recent ( 3 months) contact lens use; and (4) a current or recent (3 months) persistent corneal epithelial defect (14 days in duration measuring more than $1 \mathrm{~mm}^{2}$ ). Additional exclusion criteria for patient selection included: (1) age 75 years or greater; (2) uncontrolled hypertension (systolic blood pressure $\geq 150 \mathrm{~mm} \mathrm{Hg}$ or diastolic blood pressure $\searrow 90 \mathrm{~mm} \mathrm{Hg}$ ); (3) history of a thromboembolic event; (4) diabetes mellitus; (5) coagulation abnormalities including the use of anticoagulation medications other than aspirin; (6) current or recent ( $\triangleleft \mathrm{mo}$ ) systemic corticosteroid therapy or periocular corticosteroid injection to the study eye; (7) recent ( $\leq \mathrm{mo}$ ) change in dose or frequency of topical steroids or nonsteroidal anti-inflammatory agents; (8) ocular or periocular malignancy; (9) pregnant women, lactating women, or premenopausal women not using adequate contraception; (10) recent ( $\$ \mathrm{mo}$ ) or planned surgery; (11) investigational therapy or anti-VEGF treatment within the past 60 days. Only 1 eye from each patient was selected for inclusion in this study.

\section{Medication}

A solution of $1.0 \%$ bevacizumab was formulated by the pharmacy at Massachusetts Eye \& Ear Infirmary. Commercially available bevacizumab $(25 \mathrm{mg} / \mathrm{ml})$ was diluted in $0.01 \%$ benzalkonium chloride $(0.1 \mathrm{mg} / \mathrm{ml}, \mathrm{pH}=6.2)$ to a concentration of $10 \mathrm{mg} / \mathrm{ml}$. Study medication was stored in sterile, light-protected dropper containers at 2 to $8^{\circ} \mathrm{C}\left(36\right.$ to $\left.46^{\circ} \mathrm{F}\right)$.

\section{Treatment Protocol}

All patients were provided with a solution of $1.0 \%$ bevacizumab. Treatment was administered via topical ocular instillation either $2(n=5)$ or $4(n=15)$ times per day over a period of 3 weeks. Patients were instructed to continue their usual ophthalmic medication regimens. Punctal plugs were placed in the patients' superior and inferior puncta for the duration of the treatment ( 3 weeks) to minimize systemic drug absorption. The duration of treatment was limited to 3 weeks in order to minimize potential complications associated with long-term bevacizumab therapy.

\section{Follow-Up Protocol}

Study appointments were held during weeks 1, 3, 6, 12, and 24. A detailed review of medical history and a complete ocular examination including Snellen visual acuity measurement, slit lamp biomicroscopy, and central corneal thickness measurement were performed during each visit. Digital corneal photography was performed at the baseline visit and weeks 3, 6, 12, and 24. Blood pressure was monitored at all visits. 


\section{Safety Measures}

The occurrence of ocular and systemic adverse events was closely monitored over the course of this study. Ocular adverse events were monitored through complete ocular examinations along with visual acuity measurement, intraocular pressure measurement, biomicroscopy, and corneal fluorescein staining. Systemic adverse events were identified through physical examinations, patient questioning, and blood pressure measurements taken throughout the study period.

\section{Efficacy Measures}

The primary measures of efficacy were the size and extent of corneal NV. The efficacy of bevacizumab in the treatment of corneal NV was evaluated by comparing corneal photographs taken at baseline with corneal photographs taken at follow-up visits. Secondary measures of efficacy included best-corrected visual acuity and central corneal thicknesses. Three primary metrics of corneal NV (Figure 1) were investigated: (1) neovascular area, the area of the corneal vessels when they are projected into the plane of a photograph; (2) vessel caliber, the mean diameter of the corneal vessels; and (3) invasion area, the fraction of the total corneal area into which the vessels extend. ${ }^{18}$ Digital slit-lamp corneal pictures were analyzed morphometrically using graphic editing software Photoshop CS2 (Adobe Systems Inc.; Berkeley, CA) and a program written in MATLAB® (MathWorks Inc.; Natick, MA). Through the use of the aforementioned software, we outlined the total corneal area and enhance blood vessel visibility with manual tracing. The non-vessel areas were excluded using a defined threshold while the remaining neovascular area was pixelated for quantification. Vessel area was normalized to the entire corneal area in order to obtain a neovascular area score for each cornea. Vessel caliber was calculated using a computational technique that measures the largest diameter circle (centered at each pixel) inside of a blood vessel. The mean value across all pixels within the vessels was used as an estimate of the mean vessel caliber for a given image. Invasion area was quantified by marking the end of all vascular sprouts and connecting these marks in order to define the contour of the invasion area. The measured invasion area was normalized to the entire corneal area.

\section{Statistical Analyses}

All data are expressed as mean \pm standard error of the mean (SEM). To quantify changes in corneal NV, measurements in each metric were taken at each time point and were compared with their baseline values. A paired t-test was performed using 2-sided alternatives to compare cohort scores for each metric. Other tests used in this study include: correlation test, one-way analysis of variance (ANOVA), and Bonferroni's multiple comparison test. A $P$-value $<.05$ was considered statistically significant. Statistics were calculated and graphs were composed using Microsoft Excel and Prism 5, version 5.0c (GraphPad Software Inc.; San Diego, CA).

\section{RESULTS \\ Demographics}

Twenty eyes from 20 patients with stable corneal NV were included in this study. Demographic factors are listed in the Table, including each patient's age, sex, and cause of corneal NV. There were 12 male and 8 female patients included in this study with an average age of $52.5 \pm 3.3$ years $(n=20)$, ranging from 24 to 75 years. Eighteen patients completed 24 weeks of follow-up, whereas 2 patients terminated their study visits at week 6 due to non-study medication related issues. 


\section{Neovascular Area}

There was a reduction in neovascular area by the end of the 3 -week treatment period compared to baseline (Figure 2), but this was not statistically significant (mean $=-12.2 \% \pm$ $9.9 \% ; \mathrm{n}=20 ; P=.234)$. There was a statistically significant decrease by week 6 (mean $=$ $-27.9 \% \pm 9.2 \% ; \mathrm{n}=20 ; P=.007)$, which was 3 weeks after the termination of treatment. Statistically significant reductions in neovascular area were also observed at week 12 (mean $=-35.0 \% \pm 11.9 \% ; \mathrm{n}=18 ; P=.009)$ and week 24 (mean $=-47.5 \% \pm 8.8 \% ; \mathrm{n}=18 ; P<$. 001). Interestingly, there was a significant decrease in neovascular area at week 24 when compared to week 3 (mean $=-28.5 \% ; P=.002)$, indicating a delayed yet sustained medication response. The response rate, defined as the percentage of patients showing reduction in corneal $\mathrm{NV}$ when compared to baseline, was $65.0 \%$ (13 out of 20 patients) for neovascular area at week $3,85.0 \%(17 / 20)$ at week $6,77.8 \%(14 / 18)$ at week 12, and $88.9 \%$ $(16 / 18)$ at week 24.

\section{Vessel Caliber}

There were decreases in vessel caliber at week $3($ mean $=-8.8 \% \pm 9.3 \% ; \mathrm{n}=20 ; P=.355)$ and week 6 (mean $=-9.0 \% \pm 13.4 \% ; \mathrm{n}=20 ; P=.510)$ when compared with baseline, but these were not statistically significant (Figure 2 ). A statistically significant decrease (mean = $-30.8 \% \pm 9.8 \% ; \mathrm{n}=18 ; P=.006$ ) was observed by week 12 , which was 9 weeks after the termination of treatment. At week 24 , there was a statistically significant reduction in vessel caliber compared with baseline $(P=.003)$. The mean change at week 24 was $-36.2 \% \pm$ $9.3 \%(\mathrm{n}=18)$ with a range from 59.4 to $-99.9 \%$. There was also a significant decrease in vessel caliber between weeks 3 and 24 (mean $=-22.3 \% ; P=.009$ ), indicating a delayed medication response. The response rate in vessel caliber was $60.0 \%(12 / 20)$ at week 3 , $65.0 \%(13 / 20)$ at week $6,88.9 \%(16 / 18)$ at week 12 , and $83.3 \%(15 / 18)$ at week 24.

\section{Invasion Area}

The reductions in invasion area from baseline were $-3.6 \% \pm 7.1 \%(\mathrm{n}=20)$ at week 3 and $-20.0 \% \pm 9.9 \%(\mathrm{n}=18)$ at week 24 (Figure 2). Compared to baseline, no statistically significant change in invasion area was noted at either week 3 or week $24(P=.62$ and .06 , respectively). The response rate in invasion area was 50\% (10/20) at week 3, 55\% (11/20) at week $6,55.6 \%(10 / 18)$ at week 12 , and $66.7 \%(12 / 18)$ at week 24.

\section{Drug Efficacy Relative to the Severity of Neovascularization and Background Etiology}

Treatment response was defined as a measurable decrease in a corneal NV quantification metric as compared to baseline. By week 24, patients who responded to treatment $(n=15$ out of 18) exhibited a correlation between the baseline level of invasion area and measured decreases in neovascular area and vessel caliber ( $P=.049$ and .015 , respectively) (Figure 3 ). For the purpose of additional analysis, these patients were separated into 3 distinct groups based on NV etiologies: (1) herpes simplex virus keratitis/herpes zoster ophthalmicus (HSV/ $\mathrm{HZO}, \mathrm{n}=4)$, (2) penetrating keratoplasty (PKP, $n=5$ ), and (3) limbal stem cell deficiency (LSCD, $\mathrm{n}=4$ ). Differences in treatment response were analyzed using ANOVA (analysis of variance) and Bonferroni's multiple comparison test. Statistical analysis revealed that the improvements (decreases) in neovascular area for the HSV/HZO and LSCD groups were significantly greater than the improvement for the PKP group over the course of this study $(P=.004$, ANOVA; HSV/HZO vs PKP: $P<.01$, LSCD vs PKP: $P<.05$, Bonferroni's multiple comparison test) (Figure 4, top). A similar statistically significant trend was noted in vessel caliber change for the HSV/HZO and LSCD groups when compared to the PKP group $(P=.005$, ANOVA; HSV/HZO vs PKP: $P<.01$, LSCD vs PKP: $P<.05$, Bonferroni's multiple comparison test) (Figure 4, bottom). 


\section{Secondary Outcomes Measures}

Snellen visual acuity values were converted to LogMAR equivalents for analysis. Mean corrected LogMAR visual acuity was 0.60 at the baseline visit, 0.63 at week 3 , and 0.70 at week 24. Changes in visual acuity from baseline were not statistically significant at any of the follow-up time points. With no statistically significant differences observed over time, the mean central corneal thickness measurements were $484.1 \mu \mathrm{m}$ at baseline, $506.6 \mu \mathrm{m}$ at week 3 , and $510.9 \mu \mathrm{m}$ at week 24 . No significant effect of topical bevacizumab was noted on either best corrected visual acuity or central corneal thickness.

\section{Adverse Events}

Mean arterial pressure (MAP; [ $2 *$ diastolic blood pressure $)+$ systolic blood pressure $] \div 3$ ) from each visit was compared to the MAP recorded at baseline. The average MAP was $93.9 \mathrm{mmHg}$ at baseline, $88.8 \mathrm{mmHg}$ at week $3(P=.09)$, and $96.1 \mathrm{mmHg}$ at the final visit $(P$ $=.24)$. There were no statistically significant changes in MAP at any of the follow-up visits. No ocular or systemic adverse events were observed or reported.

\section{DISCUSSION}

The mode of action of bevacizumab involves the binding of VEGF-A, thereby preventing VEGF-A from ligating its receptors VEGFR-1 (Flt-1) and VEGFR-2 (KDR/Flk-1). ${ }^{21,22}$ By blocking the ligation of VEGF-A, bevacizumab prevents the stimulation of vascular endothelial cell migration, proliferation, and survival, as well as vascular permeability. ${ }^{23}$ The results of our study suggest that topical bevacizumab can effectively reduce the extent of clinically stable cornea NV as measured by neovascular area and vessel caliber. Although topical bevacizumab treatment also reduced the mean invasion area, this reduction was not statistically significant. These findings substantiate the reductions in neovascular area and vessel caliber reported by Koenig et al., ${ }^{20}$ and refute the suggestion that antiangiogenic therapy can only suppress the growth of new vessels. ${ }^{24}$

The present study revealed a significant amount of variability in the calculated corneal NV quantification metrics. This is evident in the large standard deviations associated with neovascular area (Figure 2). There are several potential explanations for this variability. First, many of the underlying causes of corneal NV (e.g., herpes simplex virus keratitis $[\mathrm{HSV}] /$ herpes zoster ophthalmicus [HZO], penetrating keratoplasty [PKP], and limbal stem cell deficiency [LSCD]) have the potential to cause chronic ocular surface inflammation. There are numerous proangiogenic factors relevant to corneal NV other than VEGF-A, including basic fibroblast growth factor (bFGF), matrix metalloproteinase-2 (MMP-2), and interleukin-1 (IL-1), all of which are promoted by inflammation. ${ }^{10,25}$ Accordingly, the antiangiogenic properties of bevacizumab may be compromised by the activity of these proangiogenic factors in an inflamed ocular surface. Second, the assessment of corneal NV through capture via slit lamp microscopy is arguably not the most sensitive means of assessing minute changes in small NV fronds. Blood vessels can be obscured by fibrotic tissue or vessel exudates (lipid or protein). The use of fluorescein or indocyanine green angiography may provide better delineation of corneal vessels ${ }^{26}$ however, these techniques are susceptible to variation based on factors such as the timing of image capture.

In the present study, 15 of the 18 patients who completed 24 weeks of follow-up exhibited a decrease in vessel caliber. The patients who did not respond to therapy had underlying etiologies that included HZO (patient 7), HSV (patient 8), and a history of corneal trauma (patient 20) (Table). After excluding these non-responders from the analysis, we found that, among the responders, the smaller the invasion area at baseline, the better the response to treatment (Figure 3, Figure 5). Regression modeling revealed that increasing invasion area 
was negatively correlated with bevacizumab treatment efficacy in terms of both neovascular area and vessel caliber. These findings are similar to those of the multivariate subgroup analyses in the Minimally Classic/Occult Trial of the Anti-VEGF Antibody Ranibizumab in the Treatment of Neovascular AMD (MARINA), in which a larger choroidal NV lesion at baseline was associated with less response to ranibizumab treatment. ${ }^{27}$

Subgroup analysis revealed that patients with a history of PKP experienced less improvement in NV than patients with a history of HSV/HZO or LSCD (Figure 4, Figure 5). These findings differ from those of Koenig et al. ${ }^{20}$ In their study, patients with corneal NV associated with corneal graft failure experienced the greatest reduction in vessel diameter in response to anti-VEGF therapy. There are several potential explanations for this apparent dichotomy. All the patients in the PKP group in our study had stable NV, and most of these (4 out of 5) had significant fibrotic changes associated with extensive NV in the graft-host junction. This is in contrast to the series of Koenig et al., ${ }^{20}$ in which most of the patients had active NV covering a relatively small area of the cornea. While our data suggest that patients with stable NV can respond to anti-VEGF therapy, it is possible that the endothelial cells in more established vessels (as noted in our PKP patients) are not as VEGF-dependent as newer, more active vessels, thereby explaining, at least in part, the differences in treatment efficacy observed between these studies. ${ }^{24}$ One potential confounding factor is the fact that the PKP patients in our study also exhibited a higher average invasion area at baseline than the HSV/HZO and LSCD patients - thus, it is difficult to determine whether baseline invasion area or background disease is more significantly correlated with treatment response. Regardless, our data suggest that low baseline invasion area is a good prognostic factor for topical bevacizumab treatment response.

No local or systemic adverse events were noted and systemic blood pressure remained stable over the course of this study. Theoretically, inhibition of the widely distributed VEGF-A isoform could cause adverse events through the promotion of hypertension, bleeding, proteinuria, and thromboembolic events. A Phase III clinical trial investigating intravitreal injections of ranibizumab (Lucentis; Genentech, South San Francisco, CA) in the treatment of age-related macular degeneration revealed a slightly increased, but not statistically significant, incidence of stroke and myocardial infarction. ${ }^{28}$ Based on potential complications such as these, it is important to observe appropriate precautions. All patients in our study were given punctal plugs to minimize systemic drug absorption. In addition, patients thought to be at increased risk for these complications were excluded from participation in this study; for example, patients over 75 years of age and those with a history of uncontrolled hypertension, diabetes mellitus, or past thromboembolic events.

In our study, topical $1.0 \%$ bevacizumab was not only well tolerated with no local irritation or allergic reactions, but also safe with no episodes of corneal epitheliopathy, thinning, or other ocular side effects. Vascular endothelial growth factor is known to induce neurite growth; therefore, VEGF inhibition at the ocular surface has the potential to induce 'neurotrophic keratopathy' if the duration of the therapy is prolonged. ${ }^{29}$ Previous studies have indicated that endothelial cell density remains relatively stable following anti-VEGF treatment either intracamerally or intravitrealy. ${ }^{30,31} \mathrm{Kim}$ et al. reported that $60 \%$ (6 out of 10 eyes) of patients treated with topical bevacizumab experienced the spontaneous loss of epithelial integrity. ${ }^{19}$ However, their study used topical bevacizumab at a higher concentration (1.25\%) for a longer duration (3 months) than our study, and corneal epitheliopathy was generally diagnosed during the second month of treatment. ${ }^{19}$ Koenig et al. reported that $16.7 \%$ (5 out of 30 ) of the eyes treated with topical bevacizumab developed new onset corneal epithelial defects, and one patient experienced a spontaneous corneal perforation. ${ }^{20}$ These adverse effects occurred primarily in corneas with pre-existing epithelial defects and corneas that had recently undergone surgery, both of which were 
excluded from our study. To safeguard against possible adverse events, we used a relatively low concentration $(1.0 \%)$ of drug for a short duration (3 weeks) of treatment.

In summary, our experience suggests that short-term topical bevacizumab treatment can reduce the extent of stable corneal NV as measured by the area and caliber of vessels. Moreover, the treatment effects persisted after treatment discontinuation. Interestingly, eyes with smaller areas of stable corneal $\mathrm{NV}$ at baseline experienced greater responses to topical bevacizumab treatment than eyes with larger areas of NV invasion, a finding that warrants further investigation.

\section{Acknowledgments}

Funding/Support: This study was supported in part by grant K24 EY019098 from the National Institutes of Health and by Prevent Blindness America.

Other Acknowledgments: We thank Ms. Leila Smaga from the Massachusetts Eye \& Ear Infirmary for her invaluable support in the clinical trial management.

\section{References}

1. Chang JH, Gabison EE, Kato T, Azar DT. Corneal neovascularization. Curr Opin Ophthalmol. 2001; 12(4):242-9. [PubMed: 11507336]

2. Liesegang TJ. Epidemiology of ocular herpes simplex: natural history in Rochester, Minn, 1950 through 1982. Arch Ophthalmol. 1989; 107(8):1160-5. [PubMed: 2757546]

3. Resnikoff S, Pascolini D, Etya'ale D, et al. Global data on visual impairment in the year 2002. Bull World Health Organ. 2004; 82(11):844-51. [PubMed: 15640920]

4. Epstein RJ, Stulting RD, Hendricks RL, Harris DM. Corneal neovascularization. Pathogenesis and inhibition. Cornea. 1987; 6(4):250-7. [PubMed: 2446823]

5. Niederkorn J. Immune privilege and immune regulation in the eye. Adv Immunol. 1990; 48:191226. [PubMed: 2190450]

6. Dana MR, Streilein JW. Loss and restoration of immune privilege in eyes with corneal neovascularization. Invest Ophthalmol Vis Sci. 1996; 37(12):2485-94. [PubMed: 8933765]

7. Maguire MG, Stark WJ, Gottsch JD, et al. Risk factors for corneal graft failure and rejection in the collaborative corneal transplantation studies. Collaborative Corneal Transplantation Studies Research Group. Ophthalmology. 1994; 101(9):1536-47. [PubMed: 8090456]

8. Naldini A, Carraro F. Role of inflammatory mediators in angiogenesis. Curr Drug Targets Inflamm Allergy. 2005; 4(1):3-8. [PubMed: 15720228]

9. Folkman J. Angiogenesis in cancer, vascular, rheumatoid and other disease. Nat Med. 1995; 1(1): 27-31. [PubMed: 7584949]

10. Azar DT. Corneal angiogenic privilege: angiogenic and antiangiogenic factors in corneal avascularity, vasculogenesis, and wound healing (an American Ophthalmological Society thesis). Trans Am Ophthalmol Soc. 2006; 104:264-302. [PubMed: 17471348]

11. Amano S, Rohan R, Kuroki M, Tolentino M, Adamis AP. Requirement for vascular endothelial growth factor in wound- and inflammation-related corneal neovascularization. Invest Ophthalmol Vis Sci. 1998; 39(1):18-22. [PubMed: 9430540]

12. Philipp W, Speicher L, Humpel C. Expression of vascular endothelial growth factor and its receptors in inflamed and vascularized human corneas. Invest Ophthalmol Vis Sci. 2000; 41(9): 2514-22. [PubMed: 10937562]

13. Avery RL, Pieramici DJ, Rabena MD, et al. Intravitreal bevacizumab (Avastin) for neovascular age-related macular degeneration. Ophthalmology. 2006; 113(3):363-372. e5. [PubMed: 16458968]

14. Iturralde D, Spaide RF, Meyerle CB, et al. Intravitreal bevacizumab (Avastin) treatment of macular edema in central retinal vein occlusion: a short-term study. Retina. 2006; 26(3):279-84. [PubMed: 16508427] 
15. Avery RL, Pearlman J, Pieramici DJ, et al. Intravitreal bevacizumab (Avastin) in the treatment of proliferative diabetic retinopathy. Ophthalmology. 2006; 113(10):1695-705. e6. [PubMed: 17011951]

16. Mason JO 3rd, Albert MA Jr, Mays A, Vail R. Regression of neovascular iris vessels by intravitreal injection of bevacizumab. Retina. 2006; 26(7):839-41. [PubMed: 16963866]

17. Fallah MR, Khosravi K, Hashemian MN, et al. Efficacy of topical bevacizumab for inhibiting growth of impending recurrent pterygium. Curr Eye Res. 2010; 35(1):17-22. [PubMed: 20021250]

18. Dastjerdi MH, Al-Arfaj KM, Nallasamy N, et al. Topical bevacizumab in the treatment of corneal neovascularization: results of a prospective, open-label, noncomparative study. Arch of Ophthalmol. 2009; 127(4):381-9. [PubMed: 19365012]

19. Kim SW, Ha BJ, Kim EK, Tchah H, Kim TI. The effect of topical bevacizumab on corneal neovascularization. Ophthalmology. 2008; 115(6):e33-8. [PubMed: 18439681]

20. Koenig Y, Bock F, Horn F, et al. Short- and long-term safety profile and efficacy of topical bevacizumab (Avastin) eye drops against corneal neovascularization. Graefes Arch Clin Exp Ophthalmol. 2009; 247(10):1375-82. [PubMed: 19415316]

21. Quinn TP, Peters KG, De Vries C, Ferrara N, Williams LT. Fetal liver kinase 1 is a receptor for vascular endothelial growth factor and is selectively expressed in vascular endothelium. Proc Natl Acad Sci USA. 1993; 90(16):7533-7. [PubMed: 8356051]

22. de Vries C, Escobedo JA, Ueno H, Houck K, Ferrara N, Williams LT. The fms-like tyrosine kinase, a receptor for vascular endothelial growth factor. Science. 1992; 255(5047):989-91. [PubMed: 1312256]

23. Ferrara N, Hillan KJ, Gerber H-P, Novotny W. Discovery and development of bevacizumab, an anti-VEGF antibody for treating cancer. Nat Rev Drug Discov. 2004; 3(5):391-400. [PubMed: 15136787]

24. Cursiefen C, Hofmann-Rummelt C, Küchle M, Schlötzer-Schrehardt U. Pericyte recruitment in human corneal angiogenesis: an ultrastructural study with clinicopathological correlation. $\mathrm{Br} \mathrm{J}$ Ophthalmol. 2003; 87(1):101-6. [PubMed: 12488272]

25. Dana MR, Zhu SN, Yamada J. Topical modulation of interleukin-1 activity in corneal neovascularization. Cornea. 1998; 17(4):403-9. [PubMed: 9676913]

26. Anijeet DR, Zheng Y, Tey A, et al. Imaging and evaluation of corneal vascularization using fluorescein and indocyanine green angiography. Invest Ophthalmol Vis Sci. 2012; 53(2):650-8. [PubMed: 22205599]

27. Boyer DS, Antoszyk AN, Awh CC, et al. Subgroup analysis of the MARINA study of ranibizumab in neovascular age-related macular degeneration. Ophthalmology. 2007; 114(2):246-52. [PubMed: 17270674]

28. Rosenfeld PJ, Rich RM, Lalwani GA. Ranibizumab: Phase III clinical trial results. Ophthalmol Clin North Am. 2006; 19(3):361-72. [PubMed: 16935211]

29. Rosenstein JM, Krum JM. New roles for VEGF in nervous tissue--beyond blood vessels. Exp Neurol. 2004; 187(2):246-53. [PubMed: 15144851]

30. Pérez-Rico C, Benítez-Herreros J, Castro-Rebollo M, et al. Effect of intravitreal ranibizumab on corneal endothelium in age-related macular degeneration. Cornea. 2010; 29(8):849-52. [PubMed: 20508510]

31. Hosny MH, Zayed MA, Shalaby AM, Eissa IM. Effect of intracameral bevacizumab injection on corneal endothelial cells: an in vivo evaluation. J Ocul Pharmacol Ther. 2009; 25(6):513-7. [PubMed: 19929596]

\section{Biography}

Sheng-Fu Cheng, MD, MBA, is a cornea specialist at Shin Kong Wu Ho-Su Memorial Hospital in Taipei, Taiwan. He received his medical degree from Taipei Medical University and completed his residency training in Ophthalmology at his current institution. He completed a fellowship at The Massachusetts Eye \& Ear Infirmary and Schepens Eye Research Institute, Harvard Medical School, Boston, MA, in 2011. His areas of interest include ocular surface diseases, corneal neovascularization, and corneal transplantation. 


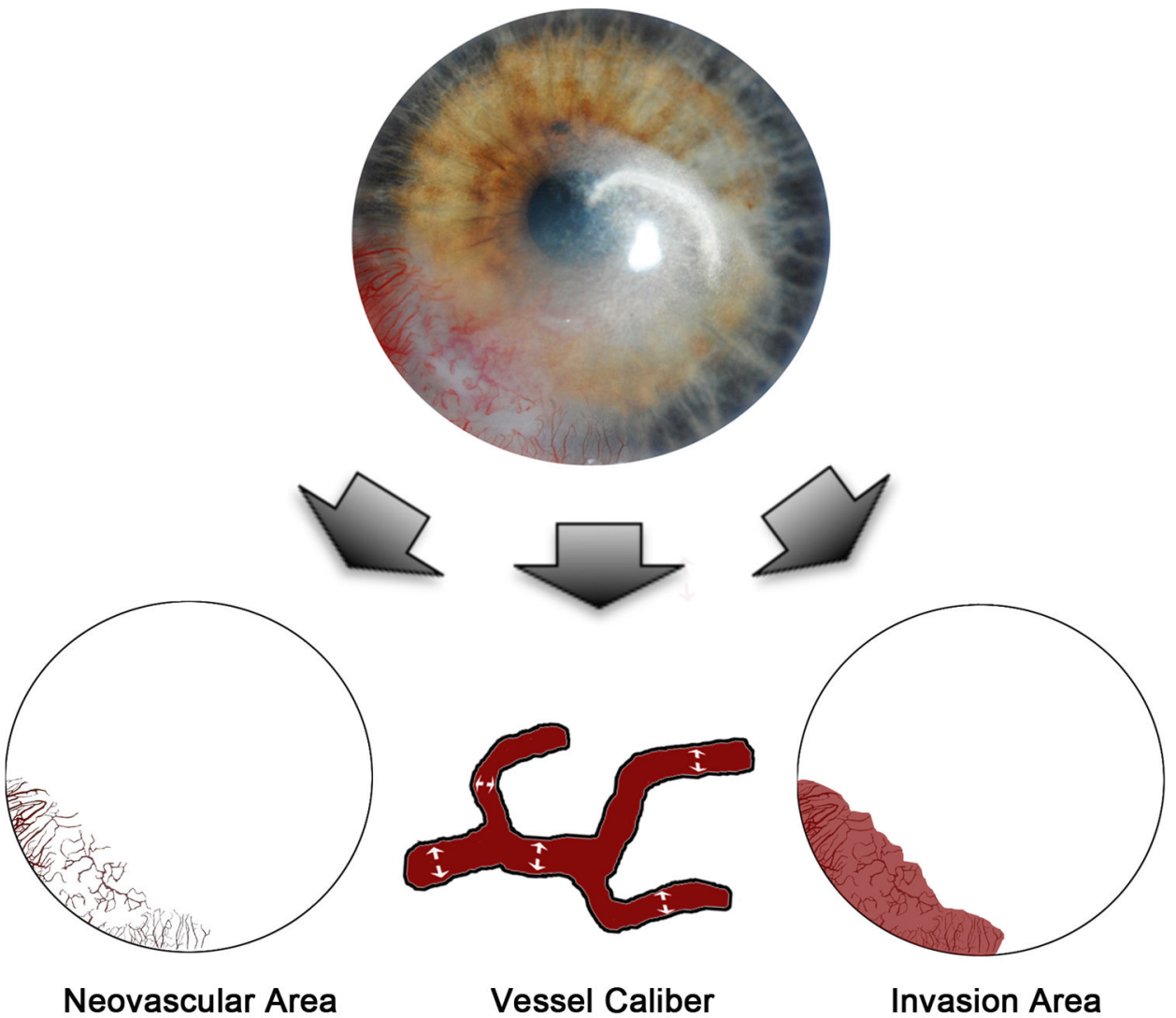

Figure 1.

Quantification of corneal neovascularization. A graphics editing software (Photoshop CS2; Adobe Systems Inc.; Berkeley, CA) and a mathematical program (MATLAB; MathWorks Inc.; Natick, MA) were used to analyze slit lamp digital corneal photographs. These metrics were computed as follows: neovascular area, which measures the area of the corneal vessels themselves; vessel caliber, which determines an approximate mean diameter of the corneal vessels; and invasion area, which measures the fraction of corneal area in which neovascular incursion is seen. 


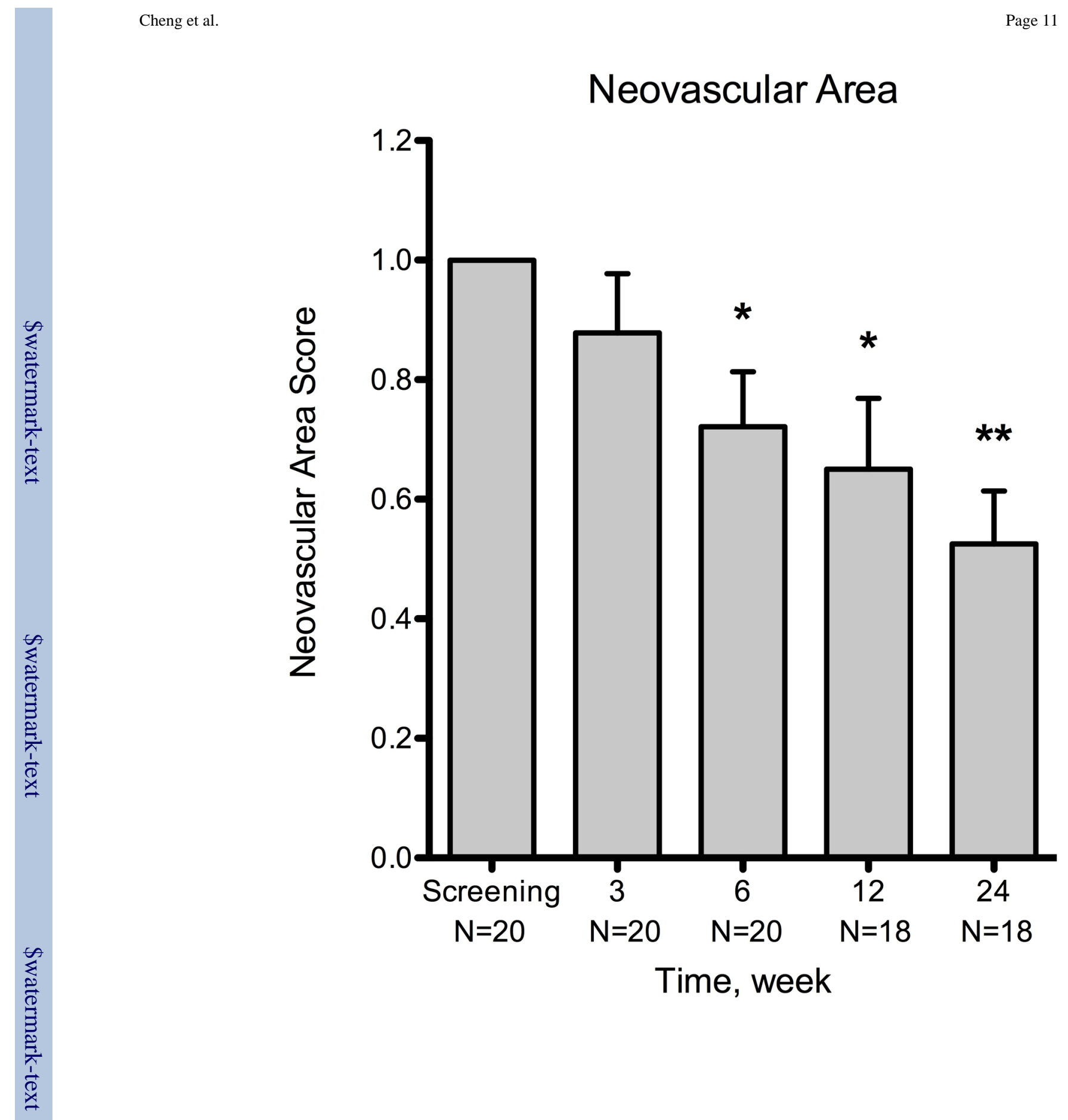




\section{Vessel Caliber}

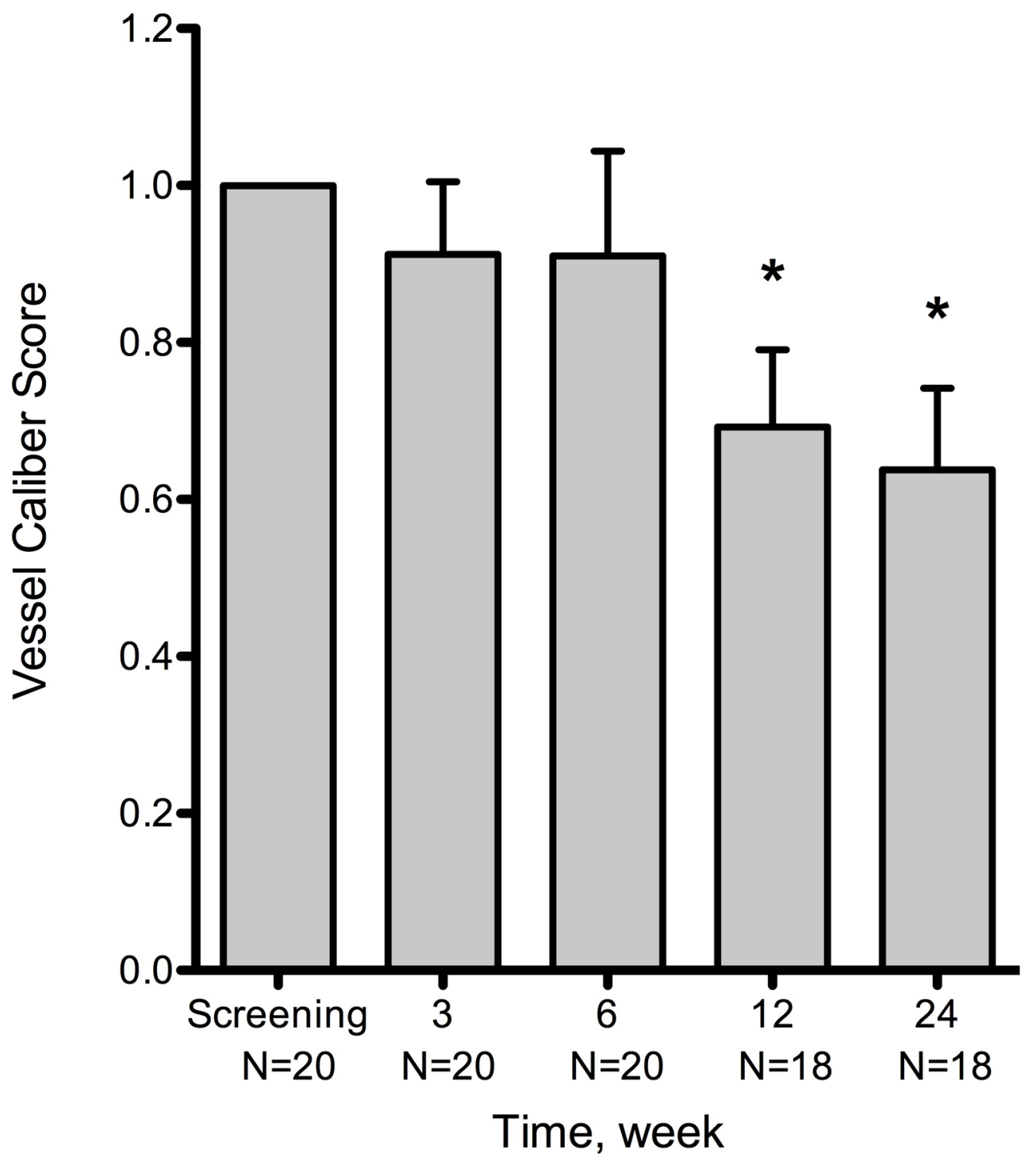




\section{Invasion Area}

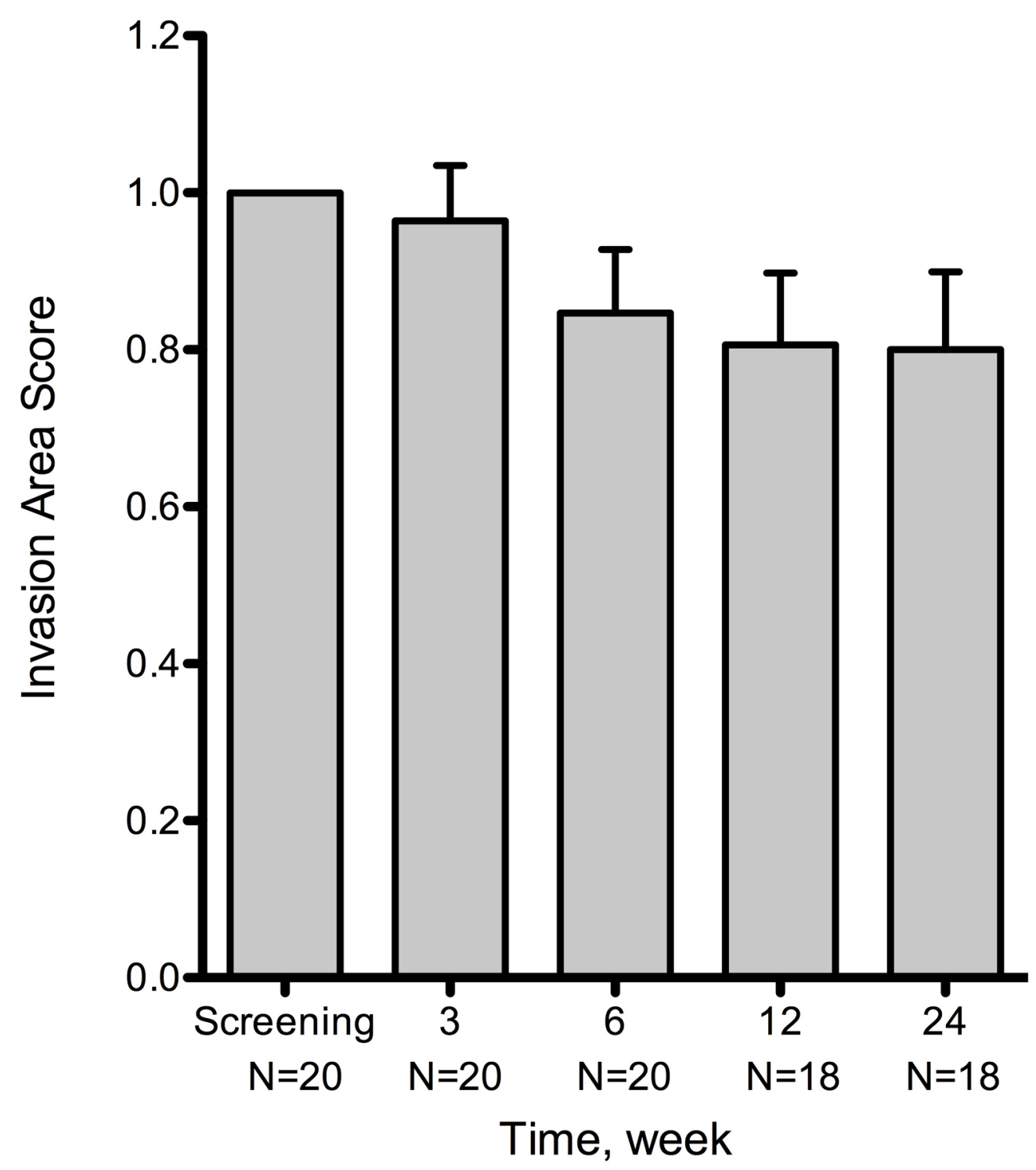

Figure 2.

Summary of changes for all patients at various time points using three metrics of corneal neovascularization. The metrics used were: neovascular area, vessel caliber, and invasion area. Compared to the baseline visit, the neovascular area showed statistically significant decrease at week $6(P=.007)$ and the vessel caliber at week $12(P=.006)$. By week 24 , the mean changes were $-47.5 \% \pm 8.8 \%(\mathrm{n}=18)$ for neovascular area, $-36.2 \% \pm 10.4(\mathrm{n}=18)$ for vessel caliber, and $-20.0 \% \pm 9.9 \%(n=18)$ for invasion area. The decreases in neovascular area and vessel caliber were statistically significant $(P<.001$ and $P=.003$, respectively), but invasion area was not $(P=.06)$. Error bars represent SEM (standard error of mean). * $P<.05, * * P<.001$ 


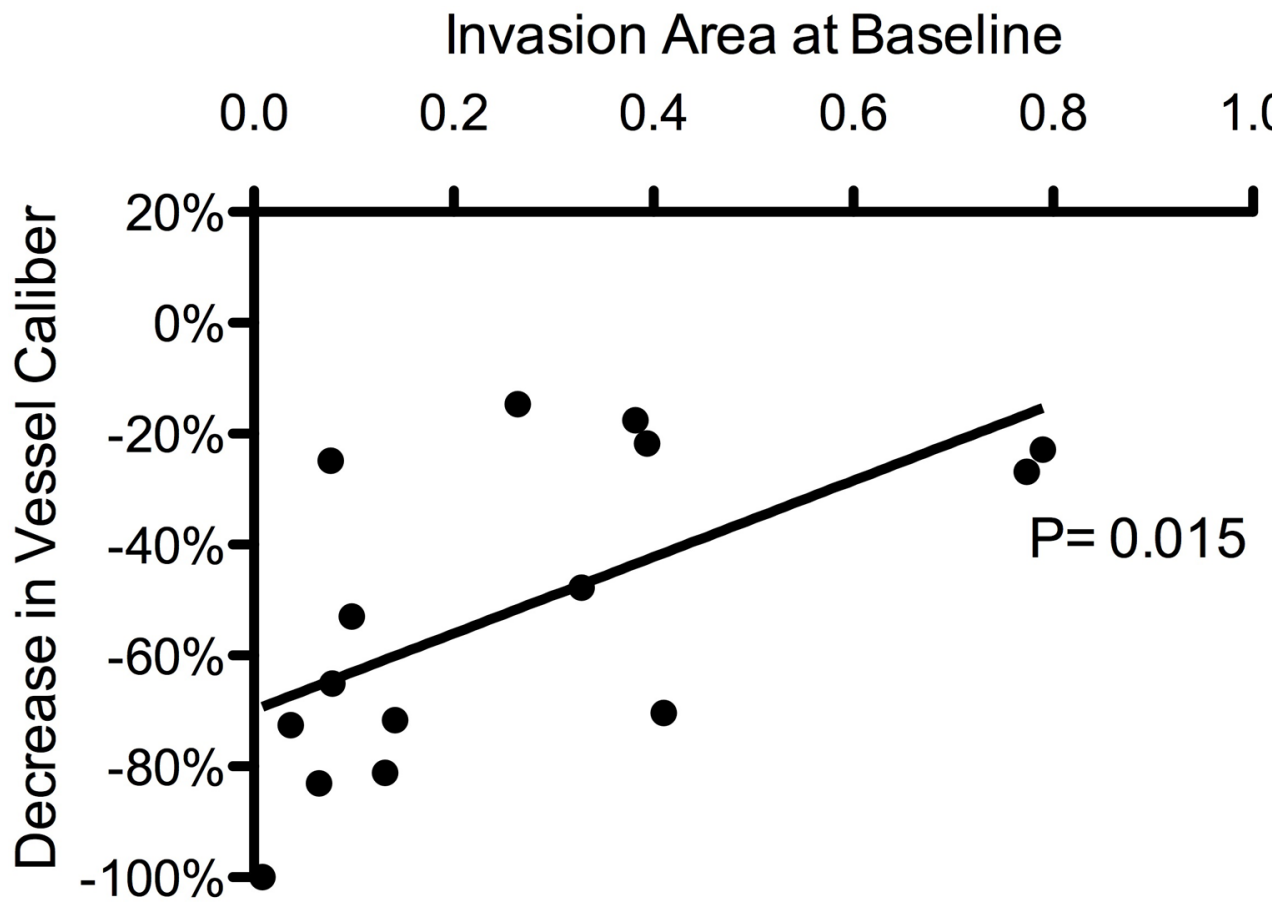

Invasion Area at Baseline

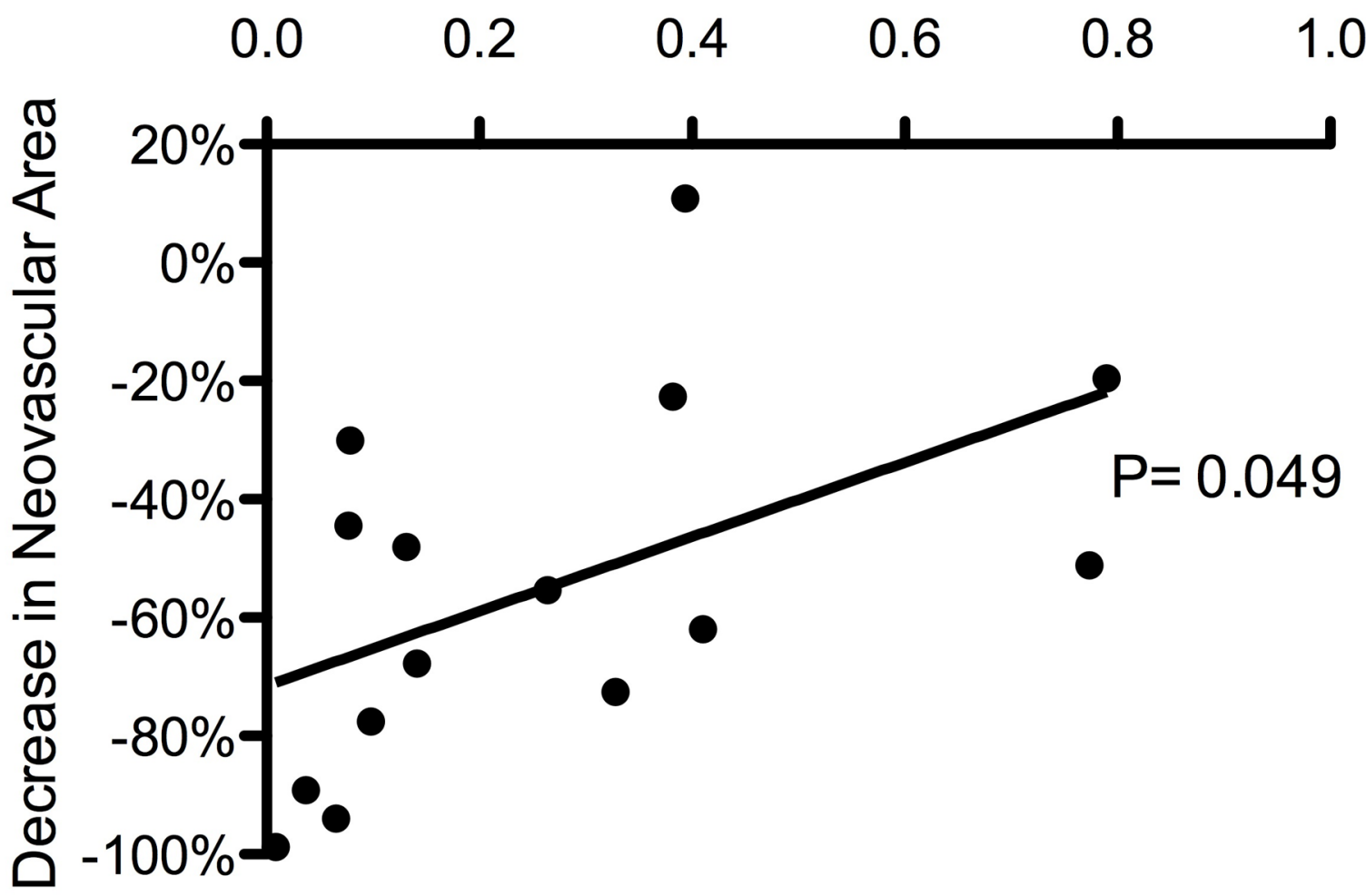

Figure 3. 
Correlation between the extent and reduction of corneal neovascularization. Patients with less invasion area at baseline experienced greater reductions in neovascular area and vessel caliber: reductions in neovascular area (Top) and vessel caliber (Bottom) showed statistically significant correlations with baseline invasion area $(P=.049$ and $P=.015$, respectively). 

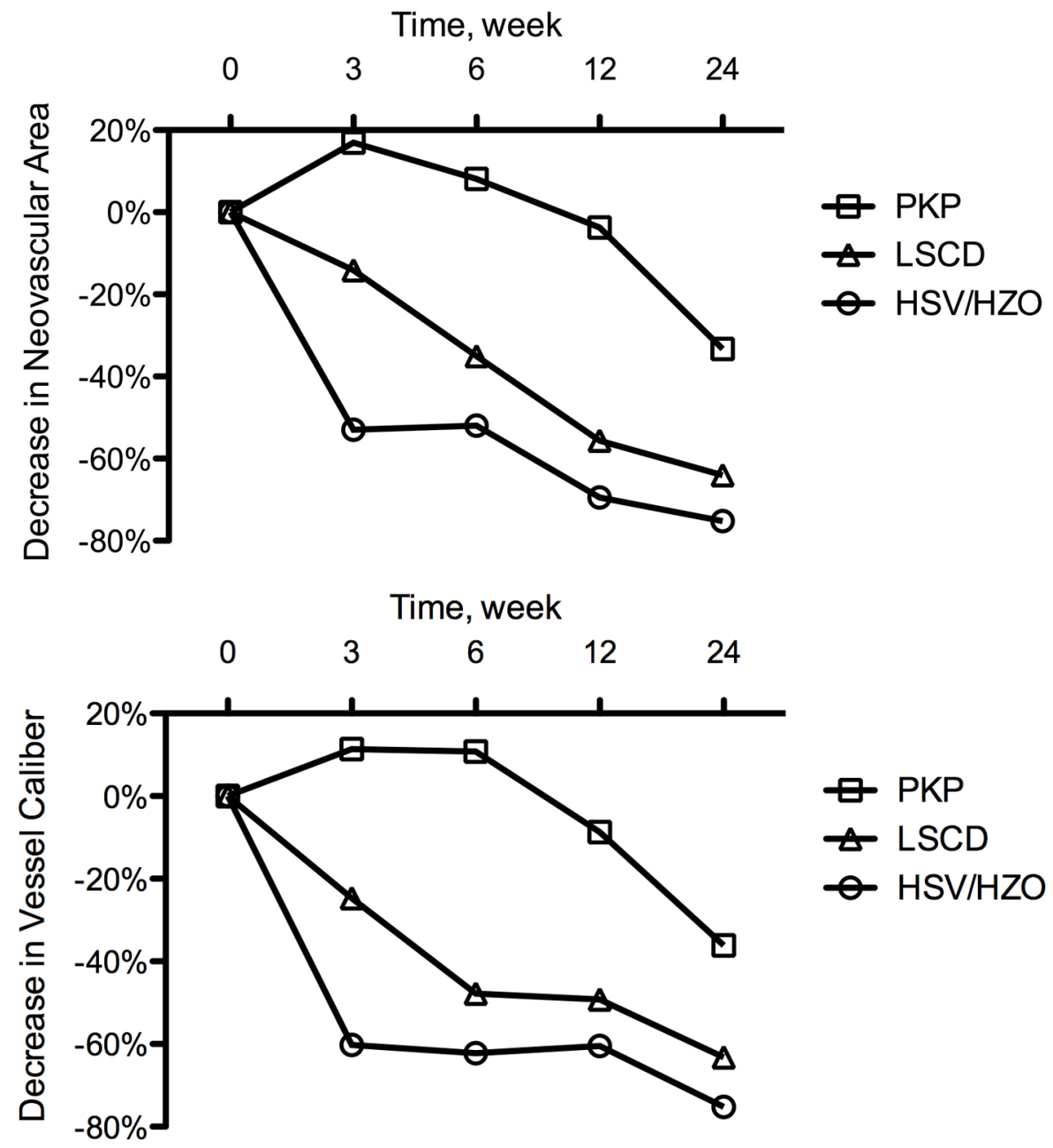

Figure 4.

Decrease in corneal neovascularization over 24 weeks of follow-up. The penetrating keratoplasty (PKP) group $(n=5)$ showed less improvement than the limbal stem cell deficiency (LSCD) group $(n=4)$ and herpetic simplex virus keratitis $(\mathrm{HSV}) /$ herpetic zoster ophthalmicus $(\mathrm{HZO})$ group $(\mathrm{n}=4)$ either in (Top) neovascular area $(P=.004$, ANOVA; HSV/HZO vs PKP: $P<.01$, LSCD vs PKP: $P<.05$, Bonferroni's multiple comparison test ) or in (Bottom) vessel caliber ( $P=.005$, ANOVA; HSV/HZO vs PKP: $P<.01$, LSCD vs PKP: $P<.05$, Bonferroni's multiple comparison test). 


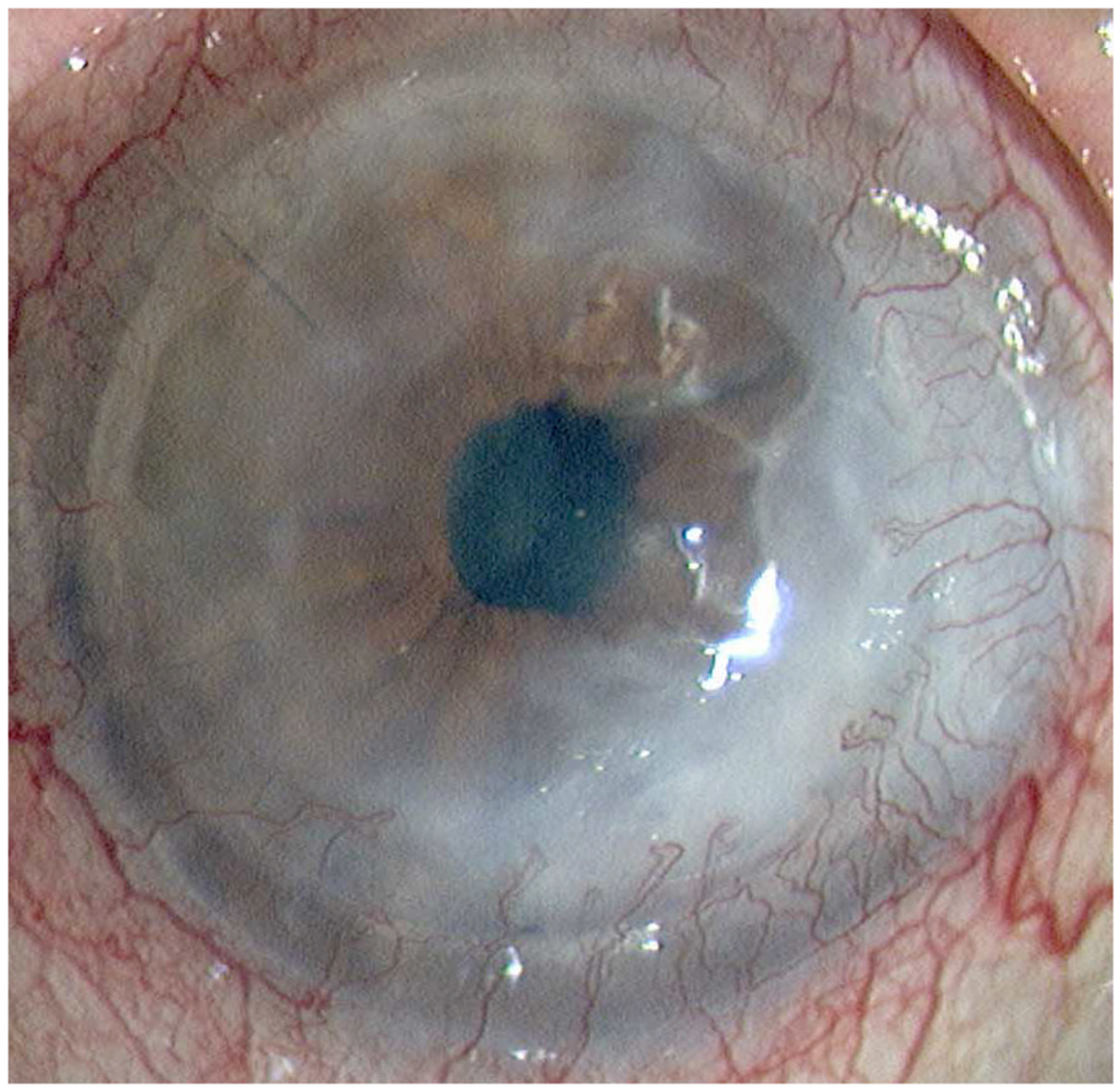




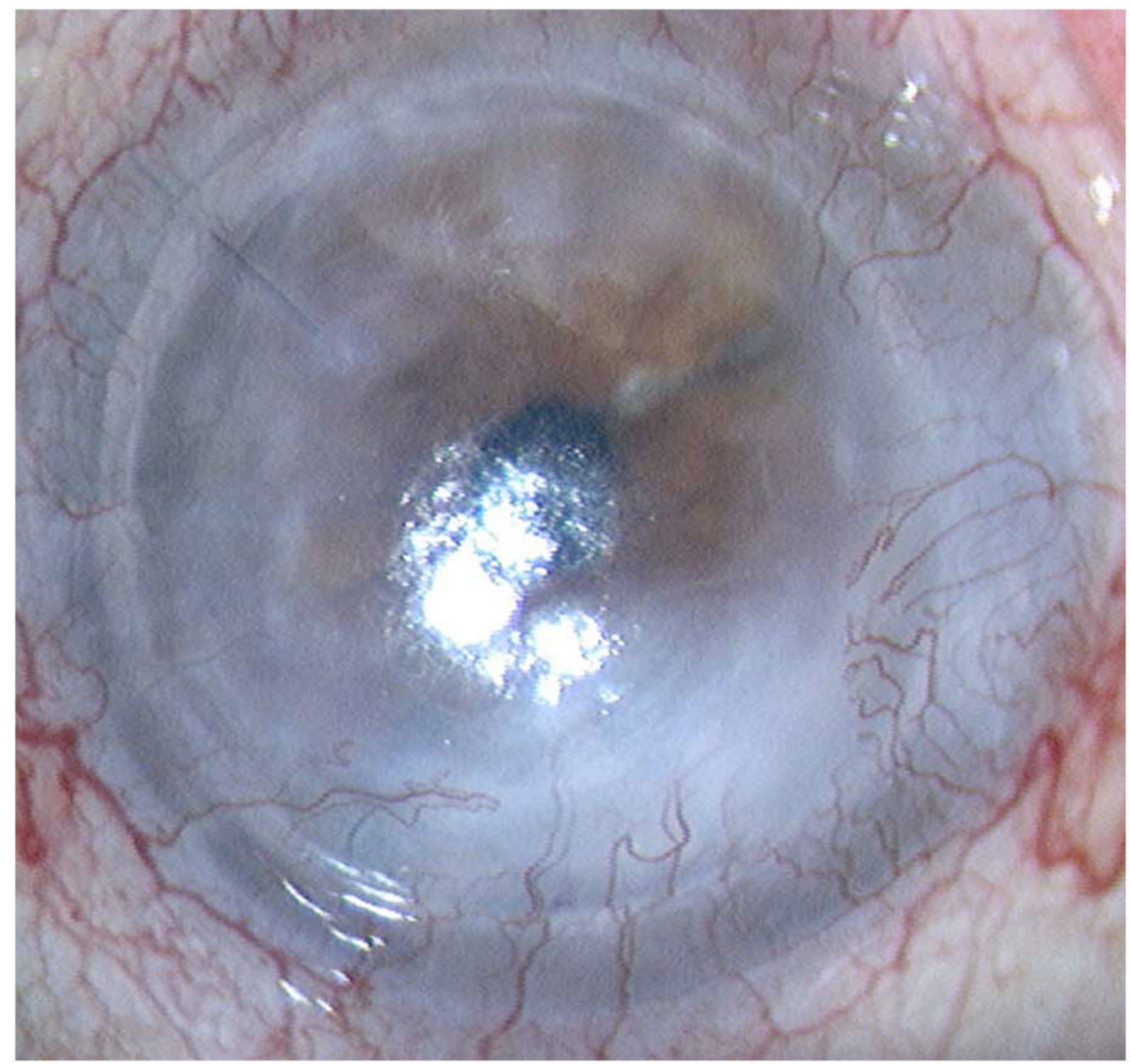




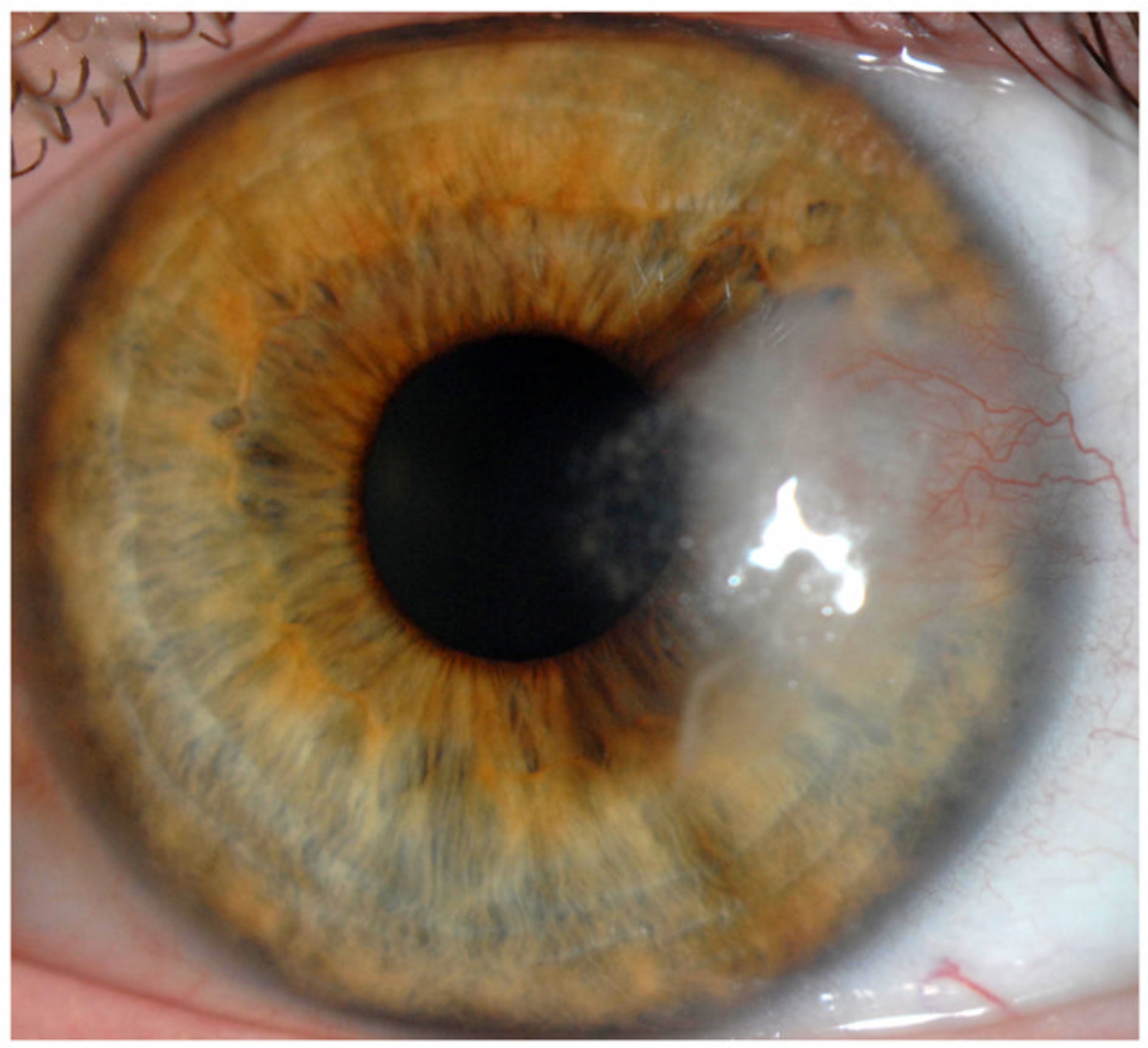




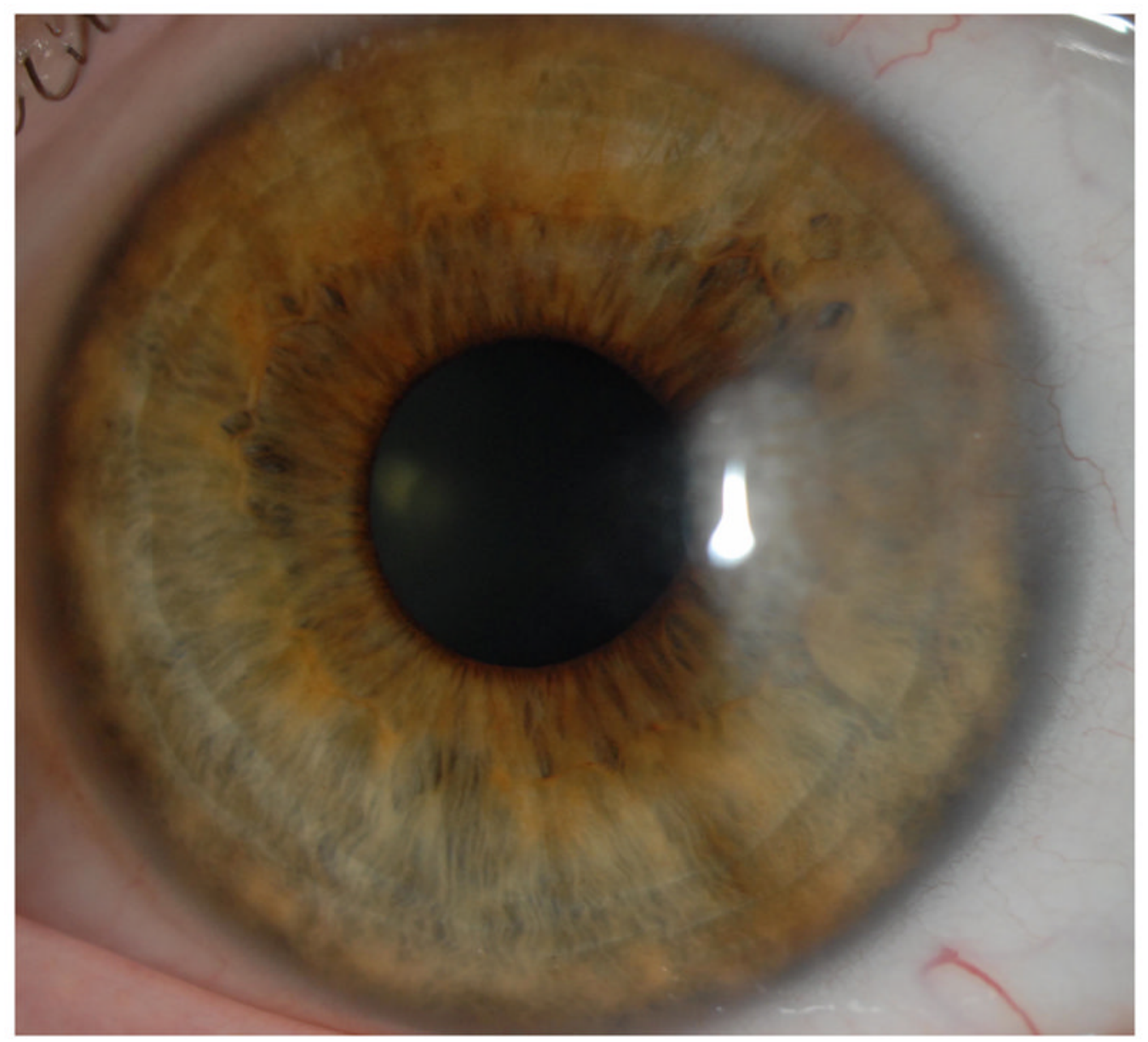

Figure 5.

Representative cases of stable corneal neovascularization treated with topical bevacizumab. Patient 11 was a 75-year-old female with a failed corneal graft. (Top left) The baseline photograph revealed a corneal opacity with circumferential (360 degrees) neovascularization (NV) in the recipient bed. (Top right) After topical bevacizumab treatment, the NV showed only modest changes. Patient 4 was a 40 -year-old male with a history of laser in situ keratomileusis and herpes simplex keratitis. (Bottom left) A relatively small area of corneal $\mathrm{NV}$ was present at baseline and by week 24 the NV had decreased significantly (Bottom right). 


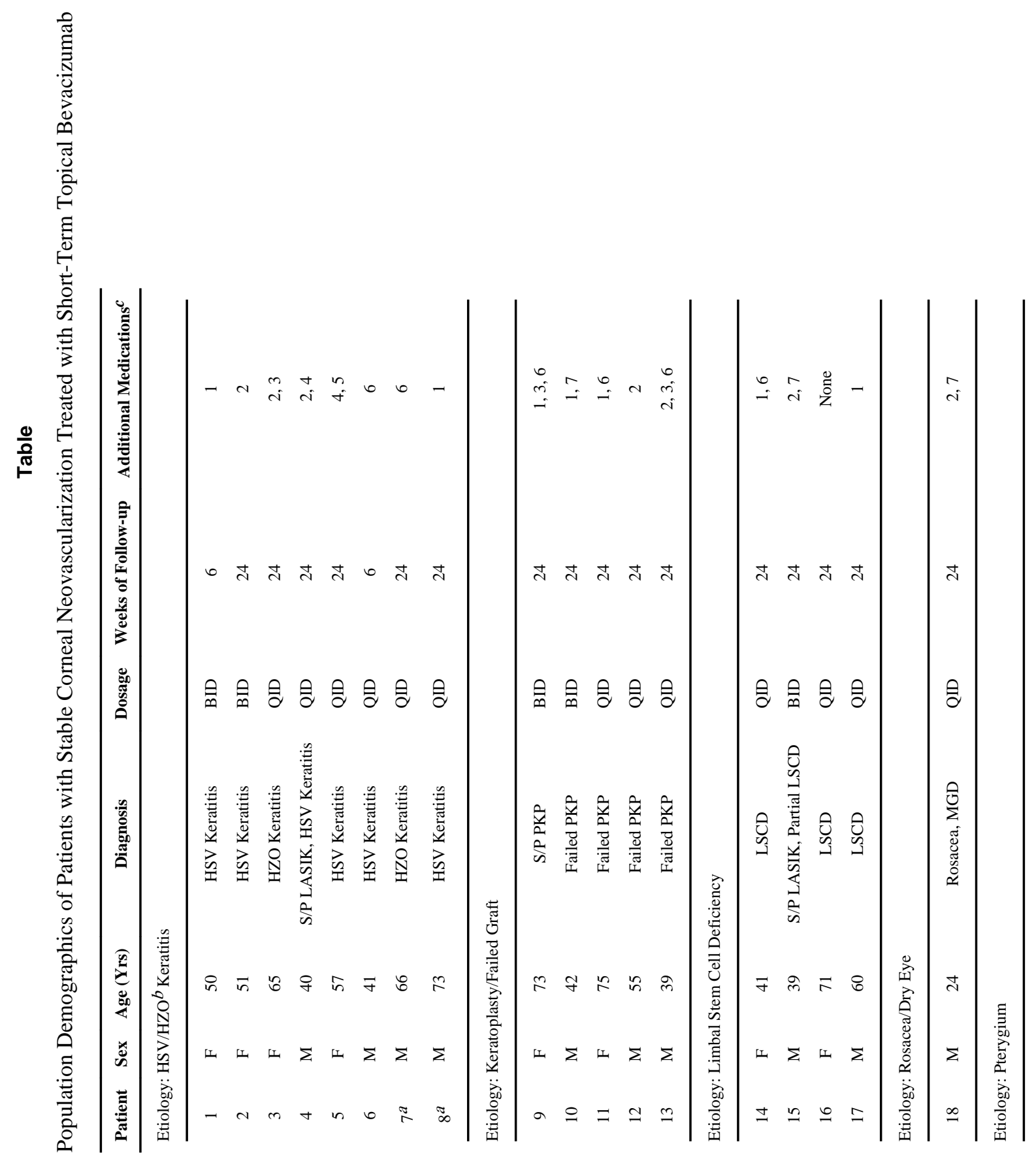




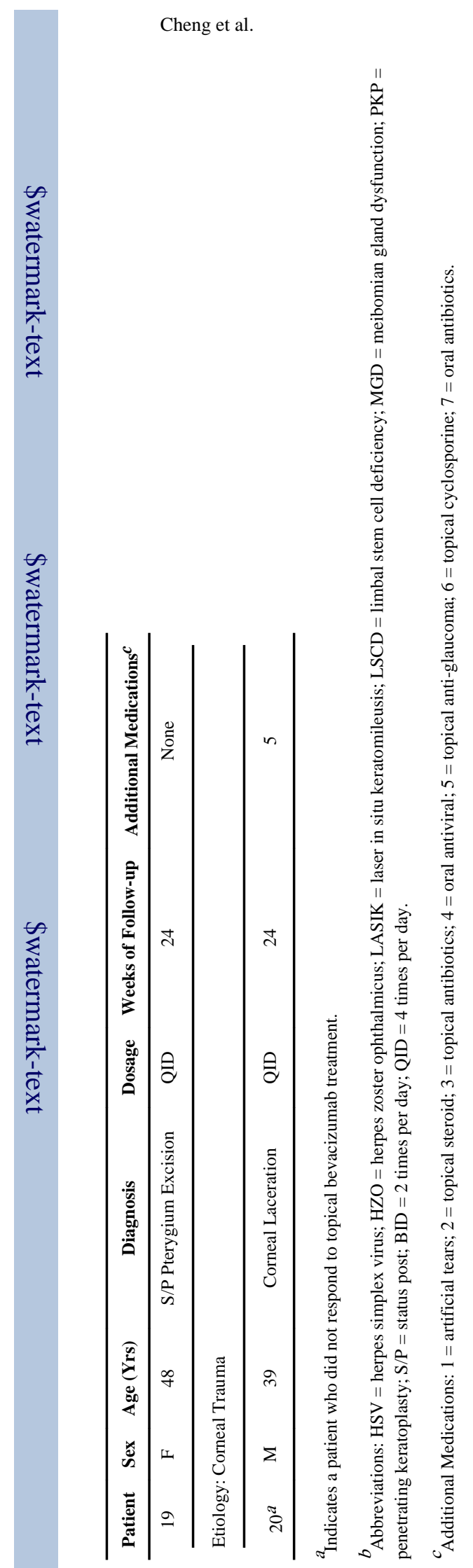

Page 22 